\title{
Xanthelasma Is Associated with an Increased Amount of Epicardial Adipose Tissue
}

\author{
Ali Rıza Akyüz ${ }^{a} \quad$ Mustafa Tarık Ağaç ${ }^{d}$ Turhan Turan $^{b}$ Sinan Şahin ${ }^{\mathrm{e}}$ Selim Kul ${ }^{\mathrm{c}}$ \\ Levent Korkmaz $^{b}$ Musluhittin Emre Erkuş ${ }^{f}$ Hakan Erkan $^{b}$ Şükrü Çelik ${ }^{b}$ \\ ${ }^{a}$ Department of Cardiology, Akçaabat Haçkalı Baba State Hospital, b Department of Cardiology, Ahi Evren \\ Cardiovascular and Thoracic Surgery Training and Research Hospital, and 'Department of Cardiology, Trabzon \\ Kanuni Training and Research Hospital, Trabzon, dDepartment of Cardiology, Faculty of Medicine, Sakarya \\ University, Sakarya, e Department of Cardiology, Bergama State Hospital, Izmir, and 'Department of Cardiology, \\ Faculty of Medicine, Harran University, Şanlıurfa, Turkey
}

\section{Key Words}

Xanthelasma · Epicardial fat thickness · Echocardiography

\begin{abstract}
Objective: In the present study, we aimed to compare the amount of epicardial adipose tissue in subjects with and without xanthelasma. Subjects and Methods: Fifty-two subjects with xanthelasma and 52 age- and gender-matched control subjects were enrolled in this study. Epicardial adipose tissue was assessed by measuring epicardial fat thickness (EFT) with echocardiography. Participants were dichotomized according to median EFT, which was $4 \mathrm{~mm}$. The group with EFT $>4 \mathrm{~mm}$ was defined as the supramedian group. Body mass index (BMI) was calculated by weight (kilograms) divided by height (meters) squared. Conditional logistic regression analysis was performed to find independent factors associated with supramedian EFT (>4 mm). $\boldsymbol{R e}$ sults: Subjects with xanthelasma had higher BMI (31.2 \pm 5.6 vs. $28.6 \pm 5.7, p=0.01)$ and higher levels of total cholesterol (216 \pm 54 vs. $181 \pm 42 \mathrm{mg} / \mathrm{dl}, \mathrm{p}<0.001)$, LDL cholesterol (142
\end{abstract}

\begin{tabular}{ll}
\hline KARGER & $\begin{array}{l}\text { ( } 2015 \text { S. Karger AG, Basel } \\
1011-7571 / 15 / 0252-0187 \$ 39.50 / 0\end{array}$ \\
E-Mail karger@karger.com & $\begin{array}{l}\text { This is an Open Access article licensed under the terms of the } \\
\text { www.karger.com/mpp }\end{array}$ \\
$\begin{array}{l}\text { Creative Commons Attribution-NonCommercial 3.0 Un- } \\
\text { ported license (CC BY-NC) (www.karger.com/OA-license), } \\
\text { applicable to the online version of the article only. Distribu- } \\
\text { tion permitted for non-commercial purposes only. }\end{array}$
\end{tabular}

\pm 45 vs. $115 \pm 36 \mathrm{mg} / \mathrm{dl}, \mathrm{p}=0.003$ ) and triglycerides (median, 154 vs. $101 \mathrm{mg} / \mathrm{dl}, \mathrm{p}=0.01$ ) than control subjects. EFT was significantly higher in subjects with xanthelasma than in controls (5.04 \pm 2.02 vs. $3.81 \pm 2.03 \mathrm{~mm}, \mathrm{p}=0.002)$. In the conditional logistic regression analysis, the presence of xanthelasma (OR, 3.55; 95\% Cl, 1.43-8.78, $\mathrm{p}=0.006)$ and lower HDL cholesterol level (OR, 0.96; 95\% Cl, 0.92-0.99, $\mathrm{p}=0.023$ ) were independently associated with supramedian EFT. Conclusion: The amount of epicardial adipose tissue found in subjects with xanthelasma was higher than in subjects without xanthelasma. In addition, the presence of xanthelasma was independently associated with supramedian EFT.

(c) 2015 S. Karger AG, Basel

\section{Introduction}

Appraisal of certain cutaneous markers may lead clinicians to suspect coronary artery disease in its subclinical phase. Xanthelasma palpebrarum (XP) is the most frequently encountered cutaneous xanthoma and has been 
shown to predict the risk of ischemic heart disease in the general population, independent of well-known cardiovascular risk factors [1-5].

Epicardial adipose tissue (EAT) is a visceral fat depot surrounding the heart and epicardial coronary arteries. Due to its paracrine and endocrine activity, secreting proinflammatory and anti-inflammatory chemokines and cytokines, it has been suggested to influence the development of coronary atherosclerosis $[6,7]$. Thus, we hypothesized that EAT might be increased in patients with XP. Therefore, the aim of the present study was to compare the amount of EAT in subjects with and without xanthelasma.

\section{Subjects and Methods}

\section{Study Populations}

Asymptomatic subjects, who were admitted to the Preventive Cardiology Clinic, Akçaabat Haçkalı Baba State Hospital for assessment of cardiovascular risk profile and primary prevention purposes, were systemically screened for the presence of cutaneous markers of cardiovascular disease from January 2011 to April 2013. Among the subjects screened, 52 consecutive XP cases and 52 age- and gender-matched healthy controls were enrolled in this study. Subjects were defined as having XP if they had sharply demarcated yellow-orange plaques on or around their eyelids (fig. 1). None of the subjects had any known or suspected cardiovascular disease. Coronary artery disease risk factors were evaluated and laboratory parameters were studied to diagnose the risk factors. Informed consent was obtained from all participants and the study protocol was approved by the Ethics Committee of the Trabzon Numune Training and Research Hospital.

\section{Measurement of EAT}

Two-dimensional transthoracic echocardiography in the left lateral decubitus position was performed using a Vivid S5 cardiovascular ultrasound system (GE Healthcare, Wauwatosa, Wis., USA). Measurements were performed by a cardiologist (T.T.) who was unaware of the subjects' clinical and demographic data. Epicardial fat was identified as an echo-free space between the outer wall of the myocardium and the pericardial layer. Epicardial fat thickness (EFT) was measured perpendicularly to the free wall of the right ventricle at the end of diastole, repeated over 3 cardiac cycles. Parasternal long-axis and short-axis views allowed the most accurate measurement of EFT in the right ventricle, with optimal cursor beam orientation in each view. Maximum EFT was measured at a point on the free wall of the right ventricular along the midline of the ultrasound beam, perpendicular to the aortic annulus, and used as an anatomic reference for this view (fig. 2). For the parasternal short-axis view, EFT was measured on the right ventricular free wall along the midline of the ultrasound beam, $2 \mathrm{~cm}$ from the ventricular septum. The average value of 3 cardiac cycles from each echocardiographic view was considered. Subjects were dichotomized according to median EFT. The group with EFT above the median was defined as the supramedian EFT group.

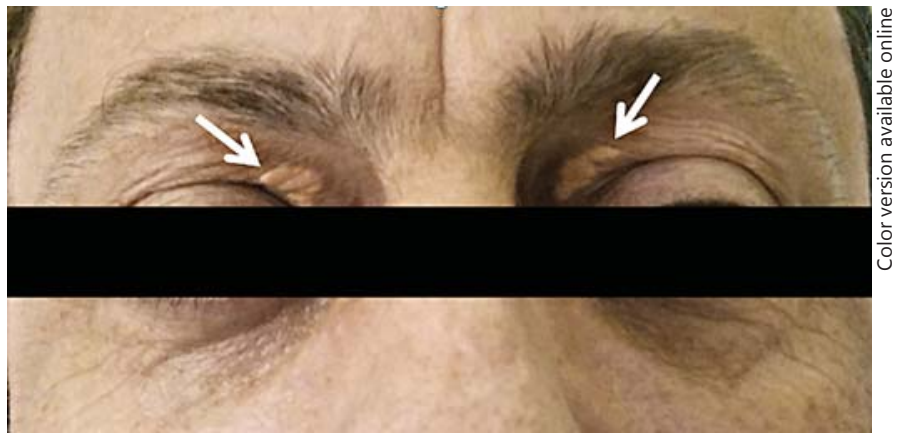

Fig. 1. XP was identified as sharply demarcated yellow-orange plaques (color in online version only) on or around the eyelids.

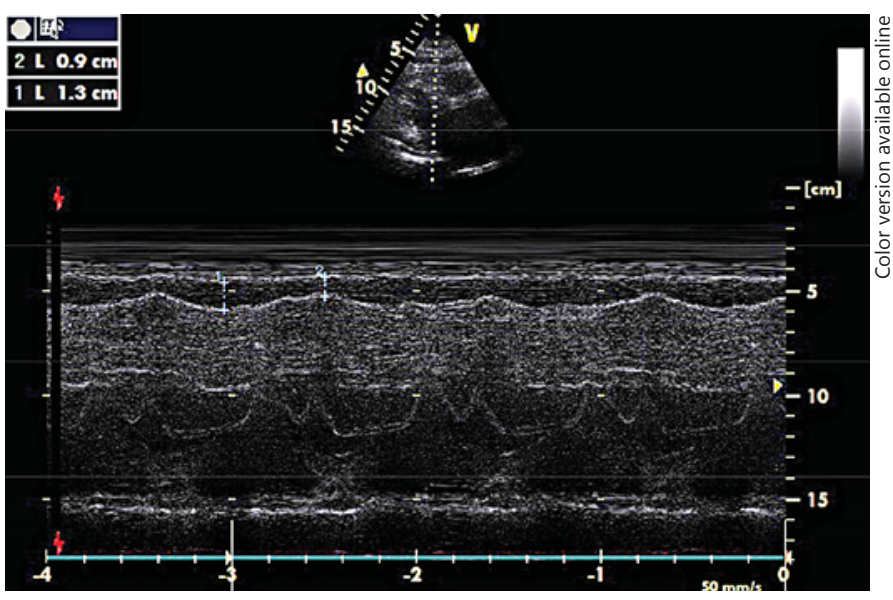

Fig. 2. Measurement of EFT by echocardiography.

\section{Statistical Analysis}

Data are expressed as means \pm standard deviations for normally distributed continuous variables, as medians and interquartile ranges for skew-distributed continuous variables and as frequencies for categorical variables. The analysis of the normality of the continuous variables was performed using the KolmogorovSmirnov test. Propensity score matching according to age and sex was done to find appropriate pairs for XP cases. The paired samples $t$ test, the Wilcoxon signed-rank test and the $\chi^{2}$ test were performed when comparing clinical and laboratory characteristics of patients and control subjects. Conditional logistic regression analysis was performed to find the independent factors associated with supramedian EFT. The covariates included in the logistic regression analysis were as follows: body mass index (BMI), total cholesterol, triglycerides, HDL cholesterol (HDL-c) and LDL-c levels, and the presence of hypertension, diabetes mellitus and xanthelasma. A p value of $<0.05$ was considered statistically significant. Statistical analysis was done by using SPSS 15.0 statistical software. 


\section{Results}

The subjects with xanthelasma had higher BMI (31.2 \pm 5.6 vs. $28.6 \pm 5.7, \mathrm{p}=0.01)$ and higher levels of total cholesterol $(216 \pm 54$ vs. $181 \pm 42 \mathrm{mg} / \mathrm{dl}, \mathrm{p}<0.001)$, LDL-c (142 \pm 45 vs. $115 \pm 36 \mathrm{mg} / \mathrm{dl}, \mathrm{p}=0.003)$ and triglycerides (median, 154 vs. $101 \mathrm{mg} / \mathrm{dl}, \mathrm{p}=0.01$ ) than control subjects (table 1). Other risk factors and HDL-c levels were similar in both groups. Median EFT was $4 \mathrm{~mm}$ in the study population. EFT was significantly higher in subjects with xanthelasma than in controls $(5.04 \pm 2.02$ vs. $3.81 \pm 2.03, p=0.002)$. Statistical power analysis yielded a power of 0.85 with the current sample size and an alpha value of 0.05 . In the conditional logistic regression analysis, the presence of xanthelasma (OR, 3.55; 95\% CI, 1.43-8.78, $\mathrm{p}=0.006)$ and lower HDL cholesterol level (OR, 0.96; 95\% CI, 0.92-0.99, p = 0.023 ) were independently associated with supramedian EFT.

\section{Discussion}

In the present study there was increased EFT in subjects with xanthelasma compared to controls and the presence of xanthelasma was independently associated with supramedian EFT.

We found higher total cholesterol, LDL-c and triglyceride levels but similar HDL-c levels in XP patients. Prior data demonstrated an apparent association between XP and dyslipidemia. Our results were similar to those of Jain et al. [8] but Bergman et al. [9] reported XP with a normal lipid profile, unlike our findings [9]. Our study revealed a female predominance in XP disease. In the literature, conflicting results have been reported with regard to sex difference in patients with XP. Although women constituted the majority of XP patients in the study by Jain et al. [8], the disease appeared more frequently in men in the study reported by Chhetri et al. [10].

We found that EFT was significantly higher in subjects with xanthelasma than in controls. Our finding of higher EAT in patients with XP suggests that XP might be associated with coronary atherosclerosis through epicardial adiposity. Indeed, earlier studies showed that atherosclerosis was more common in XP patients and subclinical atherosclerosis markers were more frequent in this patient population $[3,5]$. In their case-control study, Pandhi et al. [5] demonstrated a higher mean carotid intima media thickness in subjects with XP. They
Table 1. Comparison of clinical and laboratory characteristics between subjects with and without xanthelasma

\begin{tabular}{lccc}
\hline & $\begin{array}{l}\text { Xanthelasma } \\
\text { present } \\
(\mathrm{n}=52)\end{array}$ & $\begin{array}{l}\text { Xanthelasma } \\
\text { absent } \\
(\mathrm{n}=52)\end{array}$ & $\begin{array}{l}\mathrm{p} \\
\text { value }\end{array}$ \\
\hline Age, years & $51 \pm 10$ & $50 \pm 18$ & n.s. \\
Sex (F/M) & $40 / 12$ & $40 / 12$ & n.s. \\
Diabetes mellitus, n (\%) & $10(19.2)$ & $3(5.8)$ & n.s. \\
Hypertension, n (\%) & $23(44.2)$ & $14(26.9)$ & n.s. \\
Current smokers, n (\%) & $2(3.8)$ & $4(7.7)$ & n.s. \\
BMI & $31.2 \pm 5.6$ & $28.6 \pm 5.7$ & 0.01 \\
Total cholesterol, mg/dl & $216 \pm 54$ & $181 \pm 42$ & $<0.001$ \\
HDL-c, mg/dl & $49 \pm 13$ & $53 \pm 15$ & n.s. \\
LDL-c, mg/dl & $142 \pm 45$ & $115 \pm 36$ & 0.003 \\
Triglycerides, mg/dl & $154(109-182)$ & $101(71-142)$ & 0.01 \\
Serum creatinine, mg/dl & $0.79 \pm 0.19$ & $0.75 \pm 0.15$ & n.s. \\
EFT, mm & $5.04 \pm 2.02$ & $3.8 \pm 2.03$ & 0.002 \\
\hline
\end{tabular}

n.s. = Nonsignificant. concluded that XP patients, irrespective of their lesion sizes or serum lipid levels, should be screened using carotid intima media thickness for the detection of subclinical atherosclerosis. In their study conducted on subjects with XP, Christoffersen et al. [3] demonstrated that XP predicts an increased risk of myocardial infarction, ischemic heart disease and total death independently of well-known cardiovascular risk factors, including plasma cholesterol and triglyceride concentrations. EAT is present on the surface of the heart between the myocardium and visceral pericardium and covers more than three-quarters of the surface of the heart [7]. An increase in the quantity of EAT is associated with incident coronary artery disease and with major adverse cardiac events [11]. Several studies have demonstrated a strong association between EAT and coronary plaque burden, as well as with the presence of coronary artery disease, independent of BMI and other traditional risk factors [12, 13]. EAT is considered as one of the factors contributing to the development of coronary artery disease, similar to the other visceral adipose tissue [12]. A potential explanation of such a pathophysiological link is that the endocrine activity of EAT, as with visceral adipose tissue, results in the release of pro- and anti-inflammatory mediators and cytokines such as interleukin-6, tumor necrosis factor- $\alpha$ and adiponectin, which promote atherosclerosis [7].

There are several limitations to our study. The major limitation was the sample size in its case-control nature 
relative to the matching methodology. The study design precluded a detailed discussion of pathophysiological mechanisms responsible for increased EAT in the XP patient population. Long-term follow-up data were not obtained, hence an inference could not be drawn of increased EAT in subjects with XP. In addition, the subjects were arbitrarily dichotomized according to the sample's median EFT.

\section{Conclusion}

In the present study, there was a higher amount of EAT in subjects with than without xanthelasma. In addition, the presence of xanthelasma was independently associated with supramedian EFT.

\section{Disclosure Statement}

The authors have no conflicts of interest to declare.

\section{References}

1 Reddy SNB, Singh G, Pandey SS, et al: Clinical and lipid profile studies in xanthelasma palpebrarum. Indian J Dermatol Venereol Leprol 1983;49:127-131.

2 Sarkany RPE, Breathnach SM, Seymour CA, et al: Metabolic and nutritional diseases; in Burns T, Breathnach S, Cox N, et al (eds): Rook's Textbook of Dermatology. Oxford, Blackwell Science, 2004, vol 57, pp 57-124.

-3 Christoffersen M, Frikke-Schmidt R, Schnohr $\mathrm{P}$, et al: Xanthelasmata, arcus corneae, and ischaemic vascular disease and death in general population: prospective cohort study. BMJ 2011;343:d5497.

4 Dey A, Aggarwal R, Dwivedi S: Cardiovascular profile of xanthelasma palpebrarum. Biomed Res Int 2013;2013:932863.
5 Pandhi D, Gupta P, Singal A, et al: Xanthelasma palpebrarum: a marker of premature atherosclerosis (risk of atherosclerosis in xanthelasma). Postgrad Med J 2012;88:198-204.

6 Korkmaz L, Sahin S, Akyuz AR, et al: Epicardial adipose tissue increased in patients with newly diagnosed subclinical hypothyroidism. Med Princ Pract 2013;22:42-46.

7 Şengül C, Özveren O: Epicardial adipose tissue: a review of physiology, pathophysiology, and clinical applications. Anadolu Kardiyol Derg 2013;13:261-265.

$>8$ Jain A, Goyal P, Nigam PK, et al: Xanthelasma palpebrarum - clinical and biochemical profile in a tertiary care hospital of Delhi. Indian J Clin Biochem 2007;22:151-153.

$\checkmark 9$ Bergman R, Kasif Y, Aviram M, et al: Normolipidemic xanthelasma palpebrarum: lipid composition, cholesterol metabolism in monocyte-derived macrophages, and plasma lipid peroxidation. Acta Derm Venereol 1996; 76:107-110.
10 Chhetri MK, Chowdhury ND, De B: Xanthelasma palpebrarum: an analysis of 141 cases. J Assoc Physicians Ind 1967;15:405-412.

11 Verhagen SN, Visseren FL: Perivascular adipose tissue as a cause of atherosclerosis. Atherosclerosis 2011;214:3-10.

12 Ding J, Hsu FC, Harris TB, et al: The association of pericardial fat with incident coronary heart disease: the Multi-Ethnic Study of Atherosclerosis (MESA). Am J Clin Nutr 2009;90: 499-504.

13 Mahabadi AA, Reinsch N, Lehmann N, et al: Association of pericoronary fat volume with atherosclerotic plaque burden in the underlying coronary artery: a segment analysis. Atherosclerosis 2010;211:195-199. 